\title{
OHMIC CONTACTS TO GaAs: FUNDAMENTALS AND PRACTICE
}

\author{
A. Protrowska \\ Institute of Electron Technology, Al. Lotników 32/46, 02-668 Warszawa, Poland
}

Recent advances in the technology and understanding of ohmic contacts to $\mathrm{GaAs}$ are presented. The paper emphasizes the reactions at the metal/GaAs interface and the structural factors which govern its electrical behavior and long-term stability. Results on the optimization of conventional gold-based ohmic contacts together with recent achievements in the technology of non-alloyed contacts are overviewed.

PACS numbers: $73.40 . \mathrm{Ns}$

\section{Criteria for a good ohmic contact}

Modern device concepts strongly depend on reliable and well-controlled electrical contacts through which one has to communicate with the interior of the device from the outside world. In particular, micron and submicron size III-V devices can be fully exploited only with adequate ohmic contacts. In addition to a wide variety of device and circuit applications, good quality ohmic contacts are required for investigating the physical and electrical properties of bulk materials and related III-V heterostructures. Consequently, much attention has been recently devoted to the development of ohmic contacts to III-V materials, and the research area include both, the fundamental behavior of metal/semiconductor contacts and the new tecliniques for improving the properties of ohmic contacts [1-7].

The purpose of this paper is to bring together much of the fundamental and practical knowledge on the formation of ohmic contacts to GaAs. First, we give brief overview of the requirements for olmic contacts in modern GaAs devices. Next, we shall comment on the actual state of understanding of the formation of potential barriers developing at metal/GaAs interfaces. While the detailed discussion of theories of metal/GaAs interface is beyond the scope of this article, basic concepts applicable to fabricate low-resistance contacts will be provided. The main part of the paper is devoted to up-to-date approaches in the fabrication of ohmic contacts. We shall emphasize the reactions at the metal/semiconductor interface and the structural factors which govern its electrical behavior and long-term stability. Key technological issues of advanced contact technology will be given in Sec. 4.

The main constraint on the choice of material for an ohmic contact is to ensure that it has the correct electrical properties. They are characterized by the 
specific contact resistance $\left(r_{c}\right)$ defined as the reciprocal of the derivative of the current density $(J)$ with respect to the applied voltage $(V): r_{\mathrm{c}}=\left.\left[(\partial J / \partial V)^{-1}\right]\right|_{V=0}$. Other factors contributing to the quality of an ohmic contact depend on a given device and its specific application.

Scaling of $\mathrm{GaAs}$ devices to submicrometer dimensions imposes more stringent requirements on the characteristics of olmic contacts. Smaller intrinsic resistances make the problem of low specific contact resistance more acute. Also, the requirements for fine pattern capability of metallized ohmic contacts and their structural uniformity and stability become crucial. For the Gunn diodes, LEDs and LDs $r_{\mathrm{c}}=10^{-3}-10^{-5} \Omega \mathrm{cm}^{2}$ has been adequate, for submicrometer devices, e.g. high electron mobility transistors (IIEMTs), heterojunction bipolar transistors (HBTs), $r_{\mathrm{c}}$ should be reduced to low $\times 10^{6} \Omega \mathrm{cm}^{2}$. Fine pattern capability is necessary for minimizing the gate-to-source spacing in all types of FETs. Vertical scaling of ohmic contact is extremely important in thin-base IIBTs to avoid contact penetration into the adjacent active region and/or short-circuited collectors. Vertical scaling of source and drain contacts is highly required to take the full advantage of IIEMT making ohmic contact directly to the two-dimensional electron gas channel. Non-homogeneity of the contact structure leads to the non-uniformities current density and causes reliability problems. Surface roughness reduces device yield, especially when multilevel interconnections and bridges are used. Residual stress in the contact region can adversely affect adhesion between the metal and $\mathrm{GaAs}$, stress-induced dislocations can contribute to device degradation. Metallization must have high thermal and electrical conductivities in order to avoid heat dissipation problem which is a serious packaging issue for the integration of devices into complex circuits. Corrosion of metallic layer during device processing and/or before wire bonding must be considered with regard to the integrity of the connections and their long-term reliability. One of the most important requirement for good olmic contact is high thermal stability during further device processing and operation. It usually involves heating at $300-400^{\circ} \mathrm{C}$ during device fabrication and packing. For some self-aligned devices which require implant activation at temperatures $800-850^{\circ} \mathrm{C}$, the formation of ohmic contacts by high temperature annealing would be desirable. High-temperature GaAs devices expect long-term stability of an ohmic contact at temperature of about $400^{\circ} \mathrm{C}$.

It is clear at present that the fabrication of good quality ohmic contacts is one of the most challenging problems in GaAs integrated circuit technology. It is also clear that, without the detailed understanding of the interplay between the crystallographic structure, the chemical composition, and the electronic properties of metal/GaAs contacts, no real progress can be made. It should be stressed that the increasing use of molecular beam epitaxy (MBE) for material growth, the availability of UHV facilities and surface sensitive techniques have basically changed this field. With these techniques it became possible to study the formation of metal/GaAs contacts by following the variations of electronic surface properties and to determine the actual band bending at metal/semiconductor interface as a function of quantity of metal deposited on well-defined surfaces.

\section{Fundamentals of metal/GaAs interface}

Under ordinary processing conditions the deposition of most metals onto a 
cleaned GaAs surfaces results in the formation of a potential barrier at metal/semiconductor interface. The height of the potential barrier is defined as the energy difference between the Fermi level at the interface, $E_{\mathrm{Fi}}$, and the conduction (valence) band gap edge and the interface for $n$-type ( $p$-type) semiconductor.

The rectifying properties of metal/semiconductor contacts were recognized at the very beginning of semiconductor physics, and the deviation from Ohm's law was first explained by Schottky [8]. While it soon became clear that the conventional Schottky model in its most elementary form does not account for the obscrvations of metal/semiconductor behavior on GaAs surfaces (as for most of them the height of interfacial barrier is metal independent), there is no consensus as to the mechanism of barrier formation at metal/GaAs interface $[9,10]$. Moreover, for more than 30 years, since first Bardeen's [11] article on highly fixed and unmovable Fermi level at metal/semiconductor interfaces we accustomed to the idea of interfacial states which pin the interfacial Fermi level in metal contacts to GaAs. On the other hand, recently, there is an increasing number of papers which report changes in the Fermi level position at metal/GaAs interfaces with accompanying changes in interface parameters of importance to device applications [12-21]. If the control in the Fermi level position at the interface can be obtained, this can be applied to ohmic contact, as well as to the Schottky barriers.

One of the examples of the importance for ohmic contact formation was presented by Waldrop and Grant [17, 18]. Evidence was given that shallow band bending can be obtained for metal contacts to $n$-GaAs when the interface composition is controlled by thin $(<3 \mathrm{~nm}) n$-type $\mathrm{Si}$ or Ge interlayers. When $\mathrm{Ge}$ and $\mathrm{Si}$ were deposited at temperature at least $200-350^{\circ} \mathrm{C}$ under conditions where $\mathrm{V}$-group element incorporation is allowed to make $n$-type $\mathrm{Si}$ and $\mathrm{Ge}$, the $E_{\mathrm{Fi}}$ values increased from $0.67 \mathrm{eV}$ for clean GaAs surface to $1.08 \mathrm{eV}$ for $\mathrm{Si}(: \mathrm{P}) / \mathrm{GaAs}, 1.23 \mathrm{eV}$ for $\mathrm{Si}(: \mathrm{As}) / \mathrm{GaAs}$ and $1.02-1.2 \mathrm{eV}$ for $\mathrm{Ge}(: \mathrm{As}) / \mathrm{GaAs}$ interface. High $E_{\mathrm{Fi}}$ position induced by these overlayers could be preserved after metal deposition by interposing a thin layer of nonmetal electrical conductor between the contact metal and the semiconductor ( $\mathrm{NiAs}_{x}$ and Te were used in experiments).

Whatever the mechanism of the barrier formation is, in principal there are three mechanisms that govern the current flow through the metal/semiconductor contact with a potential barrier: (a) thermionic emission (TE) of carriers over the top of a barrier (which gives rise to current rectification), (b) thermionic field emission (TFE), i.e. tunneling of hot carriers through the top of the barrier, and (c) field emission (FE), i.e. carrier tunneling through the whole barrier. A comprehensive analysis of the conduction properties of metal/semiconductor contacts in the TE, TFE and FE regions is presented in [3]. In the FE regime, which is the preferred mode of current transport in ohmic contacts, $r_{\mathrm{c}}$ is determined predominantly by the following factor:

$$
r_{\mathrm{c}} \sim \exp \left[\left(2 \Phi_{\mathrm{B}} / q h\right)\left(m^{*} \varepsilon / N_{\mathrm{D}, \mathrm{A}}\right)^{1 / 2}\right],
$$

where $m^{*}$ is the effective mass of tunneling carriers in the semiconductor, $\Phi_{\mathrm{B}}$ - the height of the potential barrier, $\varepsilon$ - the permittivity of the semiconductor, $N_{\mathrm{D}, \mathrm{A}}-$ the dopant concentration, $q$ - the electronic charge and $h$ - the Planck constant. Consequently, attempts to achieve contacts with linear $I-V$ characteristics and low $r_{\mathrm{c}}$ concentrate on reducing the effective barrier height and/or producing a heavily doped semiconductor layer adjacent to the metal. 


\section{Formation of ohmic contacts to GaAs}

Presenting the major technological approaches, for the sake of clarity, we will treat separately the unreacted and the heat treated metallizations. The first type of contacts will rely on a suitable preparation of the semiconductor itself so that any metal deposited on it makes the contact ohmic. The second type will require adequate metallization and subsequent thermal processing to form ohmic contact. One has to bear in mind the common problem of thermal stability required during further device processing and operation.

\subsection{In situ ohmic contacts}

From the theoretical dependence $r_{\mathrm{c}}\left(\Phi_{\mathrm{B}}, N_{\mathrm{D}, \mathrm{A}}\right)$ in the field emission regime it follows that, for high $\Phi_{\mathrm{B}}$ systems, the GaAs layer adjacent to the metallization must be doped to a level $5 \times 10^{19} \mathrm{~cm}^{-3}$ or more if good ohmic behavior is to be obtained. The best way of producing highly doped GaAs contact layer is to use MBE. Otherwise, ion implantation and diffusion can be applied to increase the doping level.

An impressive progress in heteroepitaxy of III-V semiconductors has stimulated research works on low $\Phi_{\mathrm{B}}$ semiconductor systems for ohmic contact purpose. The reduction of the $r_{\mathrm{c}}$ has been expected from the use of a heterojunction formed by the epitaxial growth of a semiconductor contact layer with suitable band gap and surface Fermi level position. This approach was first realized by using an intermediate MBE grown heteroepitaxial $\operatorname{In}_{x} \mathrm{Ga}_{1-x} A$ s layer to contact $n$-GaAs [22]. The composition of $\operatorname{In}_{x} \mathrm{Ga}_{1-x} A$ s cap layer was varied during growth from $x=0$ at the GaAs interface to $x=0.8-1.0$ at the surface. In $n$-InAs the surface states usually pin the Fermi level in the conduction band and almost any metal deposited on its surface makes the contact ohmic. The structure of an $\operatorname{In}_{x} \mathrm{Ga}_{1-x}$ As cap layer is of prime issue for obtaining low-resistance contact. The comparison of graded band gap, strained-layer superlattice (SLS), and graded band gap SLS InGaAs-cap layers was given by Shiraishi et al. [23]. As shown in Fig. 1 for a graded InGaAs interlayer, the conduction-band profile is ideally smooth but the accuracy of the

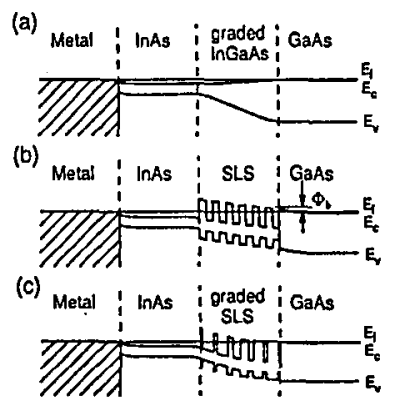

Fig. 1. Energy-band profiles of in situ ohmic contacts using (a) graded InGaAs, (b) conventional SLS, and (c) graded-SLS structures [23]. 
thickness and composition is inferior to that of an SLS structure, because the cell temperature must be changed rapidly during the MBE growth of a graded layer. For a conventional SLS interlayer, the reduction of $r_{\mathrm{c}}$ by tunneling-current conduction is expected, however the potential barrier developing at the SLS/GaAs interface increases the contact resistance. In graded band gap SLS structure this potential barrier is lower and the accurate growth control possible. TiPtAu contact with $r_{\mathrm{c}}=5 \times 10^{-8} \Omega \mathrm{cm}^{2}$ was obtained.

\subsection{Annealed ohmic contacts}

\subsubsection{Chemical reactions at metal/GaAs interfaces}

Surface sensitive techniques have clearly demonstrated that the chemical nature of 'metal/GaAs interfaces is very diverse. For room temperature depositions the systems range from the inert abrupt interfaces (i.e. $\mathrm{Ag} / \mathrm{GaAs}$ ) to those with large extent of chemical intermixing and interdiffusion (i.e. $\mathrm{Au} / \mathrm{GaAs}$ ). With regard to possible temperature and pressure conditions encountered in III-V device processing, most metals are unstable in contact with GaAs.

Two factors need special attention when analyzing metal/GaAs interfaces under heat treatment: (i) relatively low temperatures of surface decomposition of GaAs with possible volatilization of arsenic; (ii) different reactivity of GaAs surface depending on its initial construction (stoichiometry, presence of residual oxides, passivating elements, contaminations).

The temperature and pressure dependent reactions in metal/GaAs contacts lead to the formation of metal-semiconductor ternary compounds, binary phases with substantial ternary solubility, metal-semiconductor anion compounds and metal-semiconductor cation alloys. With respect to phase composition of the contact region (nucleation of first phase, sequence and final redistribution of the succeeding ones) the whole population of metal/semiconductor systems falls into several distinct classes [24]. Here, we will discuss the systems of importance for the formation of ohmic contacts and stable metallizations.

A metal which has received a great deal of attention in ohmic contact technology is indium. According to the thermodynamic data indium forms semiconducting alloys with GaAs. Annealing studies of $\mathrm{In} / \mathrm{GaAs}$ contacts give evidence that $\operatorname{In}_{x} \mathrm{Ga}_{1-x} \mathrm{As}$ interlayer of the composition dependent on the temperature of heat treatment forms at metal/semiconductor interface. $\operatorname{In}_{x} \mathrm{Ga}_{1-x}$ As phases with $x<0.2$ or $x>0.8$ form after annealing at $350^{\circ} \mathrm{C}, \mathrm{In}_{0.4} \mathrm{Ga}_{0.6}$ As phase forms at $700^{\circ} \mathrm{C}$. The microstructure of the annealed $\mathrm{In} / \mathrm{GaAs}$ contacts was shown to strongly depend on the details of contact preparation and annealing [25-30]. Since the reaction between indium and GaAs takes place at temperature above the melting point of indium, the resultant interfaces present laterally nonuniform morphologies. Moreover, the native oxide on the GaAs surface has been shown to locally inhibit the reaction.

The demonstration of epitaxial growth of $\operatorname{In}_{x} \mathrm{Ga}_{1-x}$ As phase during contact reaction In/GaAs suggesting that In-based contacts are ohmic by virtue of the formation of a heterojunction rather than by the creation of the highly doped interface region became the turning point of the history of In-based ohmic contacts. However, because of the preferred composition of $\operatorname{In}_{x} \mathrm{Ga}_{1-x} \mathrm{As}$ and the abruptness of the $\mathrm{In}_{x} \mathrm{Ga}_{1-x} \mathrm{As} / \mathrm{GaAs}$ interface ohmic behavior could not be attributed to 
the conduction through a graded $\operatorname{In}_{x} \mathrm{Ga}_{1-x}$ As layer as in the case of MBE grown heterostructure contacts. It has been proposed that in this case ohmic properties result from the reduction of barrier height by dividing the high barrier at metal/GaAs interface into two small barriers at the metal/ $\operatorname{In}_{x} \mathrm{Ga}_{1-x} \mathrm{As}$ and the $\mathrm{In}_{x} \mathrm{Ga}_{1-x} \mathrm{As} / \mathrm{GaAs}$ interfaces [30].

Gold constitutes the base of various metallization schemes for ohmic contacts to GaAs. The analysis of both, bulk thermodynamic data and thin film reactions shows that $\mathrm{Au}$ is unstable in contact with GaAs [31-36]. At room temperature a solid-state reaction was shown to produce a dilute $\mathrm{Au}-\mathrm{Ga}$ alloy and solid arsenic. At higher temperatures, the entropy change via arsenic vapor production becomes the dominant driving force for further reaction between gold and GaAs. In open system, Ga reacts with GaAs forming number of binary $\mathrm{Au}-\mathrm{GaAs}$ phases ( $\alpha$-AuGa solid solution, $\beta\left(\mathrm{Au}_{7} \mathrm{Ga}_{2}\right), \mathrm{Au}_{2} \mathrm{Ga}$, and $\left.\mathrm{AuGa}\right)$. In contrast to gallium, arsenic evaporates rapidly through the metallic layer at a rate higher than that from free $\mathrm{GaAs}$ surface. The alloyed metallization appears highly inhornogeneous both laterally and vertically with respect to the initial semiconductor surface. A typical picture of the resultant interface consists of metallic inclusions, penetrating GaAs to the depth of the order of the thickness of Au layer. In a closed system, owing to the suppression of $A s$ vaporization, the reaction between $A u$ and GaAs is restrained and, according to the ternary phase diagram, $\alpha$-AuGa phase is stable in contact with GaAs.

There are at least two reasons for nickel, palladium, and cobalt to be widely used components of ohmic metallizations to GaAs. These metals react readily with GaAs to form adherent ternary compounds or binary phases with extensive ternary solubility [37-40]. $\mathrm{Ni}_{3} \mathrm{GaAs}, \mathrm{Pd}_{2}\left(\mathrm{Ga}_{1-x} \mathrm{As}_{x}\right)$ and $\mathrm{Co}\left(\mathrm{Ga}_{1-x} \mathrm{As} x\right)$, and solid solutions of $\mathrm{Pd}_{2} \mathrm{As}$ and $\mathrm{CoAs}$ respectively form at low temperatures $\left(300^{\circ} \mathrm{C}\right.$ or less). These ternary phases are not stable at higher temperatures. The sequence of phase formation for $T>300^{\circ} \mathrm{C}$ depends on the degree of As sublimation. If As loss is limited during the reaction, the endpoint are binary phases NiGa+NiAs, $\mathrm{PdGa}+\mathrm{PdAs} \mathrm{s}_{2}$, and CoGa+CoAs. The useful feature of low-temperature reactions is that they may be reversed by subsequent reaction with another element of metallization, and thus may permit the formation of ohmic contact by solid phase reaction. Another important feature of low-temperature reactions of Ni and Pd or Co with GaAs is the ability of these metals to penetrate thin native oxides.

The most stable single element contacts to GaAs are $\mathrm{W}$ and Mo [24]. Formation of Mo-As phases at $T>700^{\circ} \mathrm{C}$ and $\mathrm{W}-\mathrm{As}$ phases at $T>750^{\circ} \mathrm{C}$ has been reported.

\subsubsection{Gold-based metallizations}

The most widely used ohmic contacts to GaAs today are gold-based metallizations heat treated for a short time at temperatures in the range $400-500^{\circ} \mathrm{C}$. The contact schemes are designed to supply a suitable dopant and possibly an additional element improving contact adhesion and/or its morphology.

The general picture explaining ohmic character of gold-based contacts is that the heat treatment drives the dopant from the metallization into the underlying semiconductor, significantly decreasing the thickness of metal/semiconductor potential barrier so that carriers may tunnel through it in the field emission regime. The metallurgy of gold-based contacts, however, has been found complex chemi- 
cally, sensitive to the large range of parameters and the understanding of the basic processes which determine ohmic behavior is still far from satisfactory.

One of the crucial questions concerns the extent of contact reaction necessary to produce ohmic contact. Also of importance is the behavior of doping species during contact annealing and the mechanism through which they participate in the formation of low-resistivity contacts. While the model of tunneling ohmic contact seems very reasonable, heavy doping at the metal/GaAs interface has not been experimentally detected. Moreover, the formation of crystalline heterojunction (graded or abrupt) or highly disordered interfacial layer could provide alternative explanations of ohmic behavior.

In order to further clarify these fundamental questions we performed the series of experiments comparing the annealing behavior of $\mathrm{Au}(\mathrm{Zn}) / p$-GaAs, $\mathrm{Au}(\mathrm{Ge}) / n$-GaAs, and $\mathrm{Au}(\mathrm{Te}) / n$-GaAs metallizations [41-51]. $\mathrm{Zn}, \mathrm{Te}$, and $\mathrm{Ge}$ were chosen as dopants which are electrically active when placed in GaAs lattice on specific sites: $\mathrm{Zn}$ occupies $\mathrm{Ga}$ sites, Te requires As vacancies, $\mathrm{Ge}$ is an arnphoteric dopant. Contacts were annealed in two configurations - either with or without an encapsulating layer. It is expected that in the closed system $\mathrm{Au} / \mathrm{GaAs}$ reaction creates preferentially $\mathrm{Ga}$ vacancies: there is a certain solubility of $\mathrm{Ga}$ in_ $\mathrm{Au}$, which at the temperature typical of ohmic contact formation can approach several tenths of an atomic percent. Ga vacancies would be required for $\mathrm{Zn}$ and Ge atoms to form acceptors and donors, respectively. $\Lambda$ s for arsenic, which is insoluble in $\mathrm{Au}$, it can accumulate at the metal/GaAs interface and/or create antisite $\mathrm{As}_{\mathrm{Ga}}$ defects. Thus, annealing under capping layer may reduce the availability of the As vacancies in the GaAs/Au interfacial region, and Te atoms would serve as a probe of the availability of such sites.

The most meaningful result of these experiments is the dissimilarity of $n$-GaAs/Au(Te) contacts annealed in closed system. While both $p$-GaAs/Au(Zn) and $n$-GaAs/Au(Ge) contacts exhibit excellent ohmic properties when annealed with an insulating cap, $n$-GaAs/ $\mathrm{Au}(\mathrm{Te})$ structures form rectifying contacts over the entire range of processing temperatures and times. The annealing behavior of capless $n$-GaAs/Au(Te), $p$-GaAs/ $\mathrm{Au}(\mathrm{Zn})$ and $n$-GaAs/Au(Ge) structures is similar to other gold-based metallizations where heat treatment is necessary to form ohmic contact and the specific contact resistance exhibits a minimum as a function of the annealing temperature. Metallurgical studies give evidence that the development and the final microstructure of the contact region strongly depend on particular dopant (its reactivity with $\mathrm{Au}$ and $\mathrm{GaAs}$ ) and annealing conditions (the use of capping layer). The net result is as follows.

Zinc reacts preferentially with gold. It forms AuZn phase in as-deposited contact, further annealing produces $\alpha-\mathrm{Au}_{3} \mathrm{Zn}$ phases. $\mathrm{Zn}$ easily penetrates the native oxide layer, and thermally activated interactions at $\mathrm{GaAs} / \mathrm{Au}(\mathrm{Zn})$ interface are dominated by the interaction between $\mathrm{Au}$ and $\mathrm{GaAs}$. In an open system, vaporization of As is the driving force of the interfacial reaction and causes extended decomposition of $\mathrm{GaAs}$ and the formation of $\alpha$-AuGa phase with $\mathrm{Ga}$ content of 11 at.\%. The presence of a capping layer limits the interaction of Au with GaAs. In this case $\alpha$-AuGa phase containing less than 1 at.\% of $\mathrm{Ga}$ forms and thus, the decomposition of $\mathrm{GaAs}$ depends on the amount of $\mathrm{Au}$ in the metallization. Figure 2 gives the total amount of arsenic losses and the corresponding specific contact resistances for uncapped and cap-annealed $\mathrm{Au}(\mathrm{Zn})$ contacts. It is important to note 


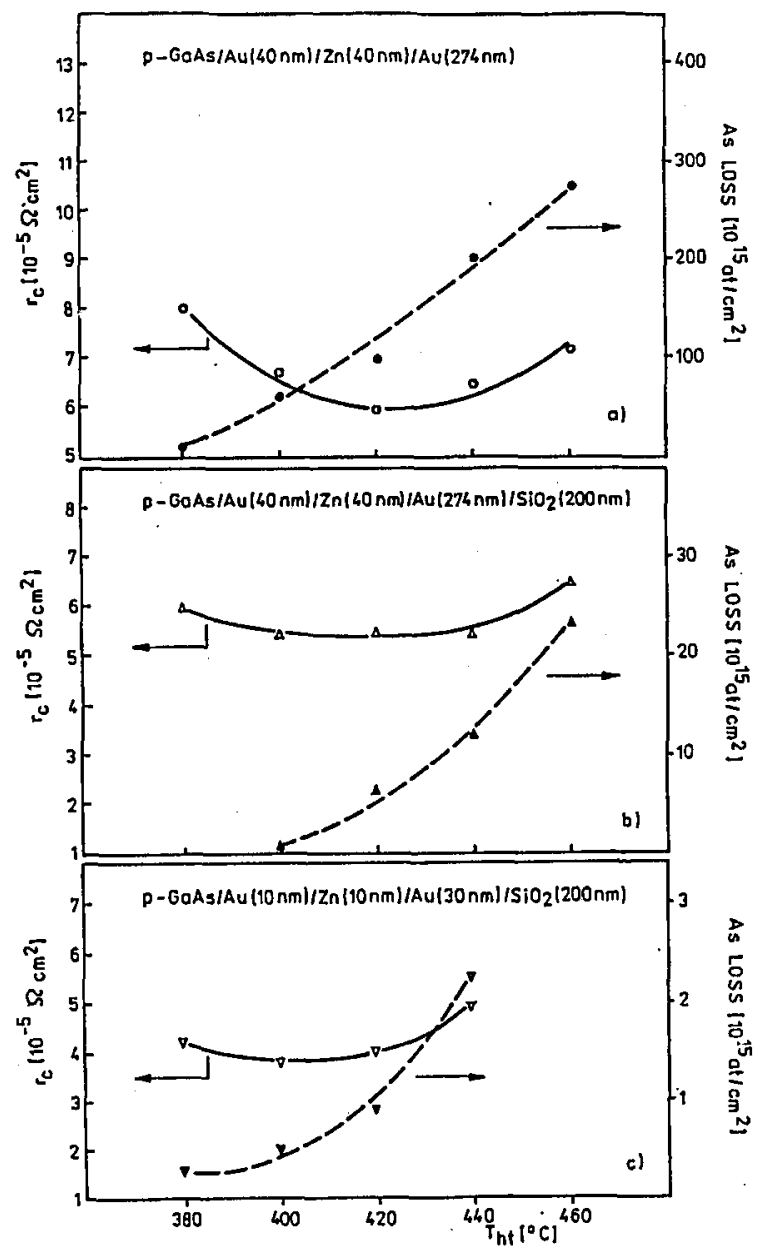

Fig. 2. The relation between As losses, the specific resistance of $p$-GaAs/Au(Zn) contacts and the temperature of heat treatment: (a) thick contact annealed without capping layer, (b) thick contact annealed with an $\mathrm{SiO}_{2}$ cap, (c) thin contact annealed with an $\mathrm{SiO}_{2}$ cap.

that the change from rectifying to ohmic behavior appears at temperatures where relatively low sublimation of arsenic occurs. These results also show that the formation of low-resistance $\mathrm{Au}(\mathrm{Zn}) / p$-GaAs contacts does not require the pronounced interaction between the metallic layer and GaAs. Assuming a perfectly homogeneous interface, the loss of As equal to $6 \times 10^{14} \mathrm{at} . / \mathrm{cm}^{2}$ corresponds to the release of one monoatomic layer of $\mathrm{GaAs}\left(6.25 \times 10^{14} \mathrm{at} . / \mathrm{cm}^{2}\right)$ during formation of ohmic contact. Figure 3 shows transmission electron microscopy (TEM) micrographs of as-deposited and cap-annealed thin $\mathrm{Au}(\mathrm{Zn}) / \mathrm{GaAs}$ contact. In as-deposited contact, continuous layer of native oxide of the thickness of $1 \mathrm{~nm}$ separates $\mathrm{Au}(\mathrm{Zn})$ 
(a)

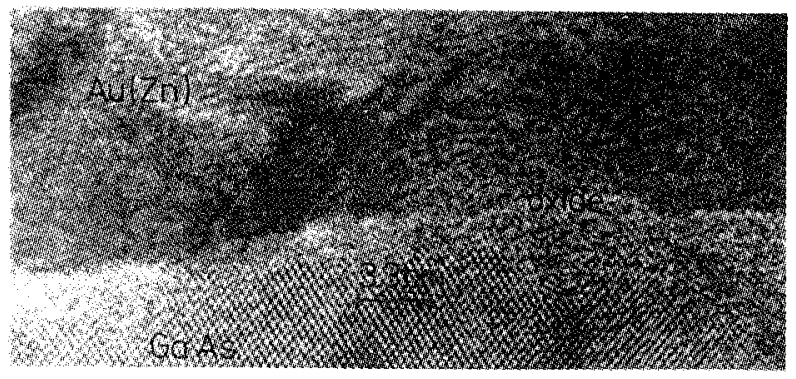

as-deposited $\mathrm{Au}(\mathrm{Zn}) / \mathrm{p} \cdot \mathrm{GaAs}$ contact

(b)

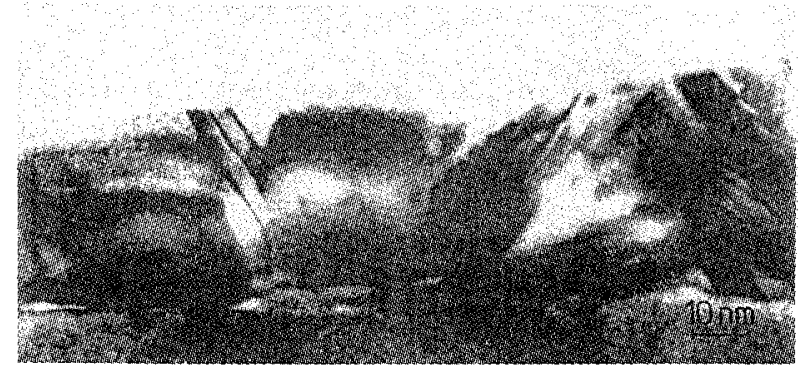

cap-annealed $\mathrm{Au}(\mathrm{Zn}) / \mathrm{p}$-GaAs contact

Fig. 3. TEM micrograph of $A u(20 \mathrm{~nm}) / \mathrm{Zn}(10 \mathrm{~nm}) / \mathrm{Au}(60 \mathrm{~nm})$ contact on GaAs: (a) as-deposited and (b) annealed at $420^{\circ} \mathrm{C}$ for 3 min with a $\mathrm{SiO}_{2}$ cap.

metallization and GaAs. Thermally activated contact reaction disperses native oxide, and leaves the interface smooth without any sign of metal/GaAs interaction.

No reaction between thin film of tellurium and gold was observed. Moreover, due to its high volatility Te sublimates in large quantities from contacts annealed in open system. In closed system, suppression of Te sublimation activates the $\mathrm{Te}-\mathrm{GaAs}$ reaction, while reduction of As vaporization restrains the $\mathrm{Au}-\mathrm{GaAs}$ reaction. $\mathrm{Ga}_{2} \mathrm{Te}_{3}$ and $\mathrm{As}_{2} \mathrm{Te}_{3}$ grown epitaxially on $\mathrm{GaAs}$ are the main products of the interaction, apart from unreacted $\mathrm{Au}$ and small quantities of $\mathrm{Au}_{7} \mathrm{Ga}_{2}$. In spite of that both $\mathrm{Ga}_{2} \mathrm{Te}_{3}$ and $\mathrm{As}_{2} \mathrm{Te}_{3}$ are low-band gap semiconductors, their formation does not lead to the formation of ohmic contacts to $n$-GaAs. In open system, contact reaction is driven by strong arsenic vaporization. Metallization forms a discontinuous layer protruding in the $\mathrm{GaAs}$ and it consists of $\mathrm{Au}$ and $\mathrm{Au}_{7} \mathrm{Ga}_{2}$ phase. It is difficult to speculate on the possible population of $\mathrm{Ga}$ and As vacancies and their occupation by Te atoms in so heavily reacted contact with an inhomogeneous interface. However, it should be stressed that such microstructure resulting from $\mathrm{Au}-\mathrm{GaAs}$ reaction, containing some $\mathrm{Te}$, without any detectable product of $\mathrm{Te}-\mathrm{GaAs}$ interaction exhibits ohmic behavior. Large evaporation of arsenic enables the incorporation of Te as an active dopant. Figure 4 shows TEM micrographs of $\mathrm{GaAs} / \mathrm{Au}(\mathrm{Te})$ contacts annealed with and without insulating cap.

The metallurgy of $\mathrm{Au}(\mathrm{Ge})$ contacts presents another picture [50]. Ge does not react with $\mathrm{Au}$ in as-deposited contacts. Upon annealing both in open and closed configurations, Ge partly regrows forming isolated grains on GaAs surface. 


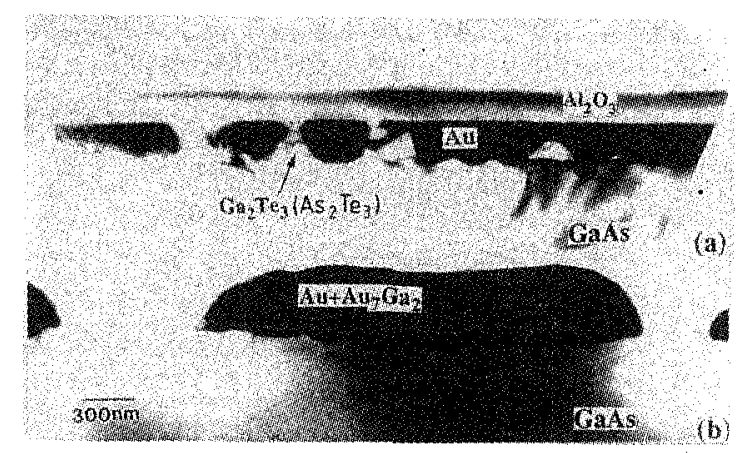

Fig. 4. TEM micrograph of $n$-GaAs $/ \mathrm{Au}(20 \mathrm{~nm}) / \mathrm{Te}(20 \mathrm{~nm}) / \mathrm{Au}(130 \mathrm{~nm})$ contact annealed at $420^{\circ} \mathrm{C}$ for $3 \mathrm{~min}$ : (a) with an $\mathrm{Al}_{2} \mathrm{O}_{3}$ cap and (b) without a cap.

At the same time Ge forms with $\mathrm{Au}$ and As the AuGeAs phase. This is why the effect of capping layer on contact reaction $\mathrm{Au} / \mathrm{GaAs}$ is less pronounced. The As losses are low and the $\mathrm{Au}-\mathrm{Ga}$ reaction limited. Consequently, the microstructures of $\mathrm{GaAs} / \mathrm{Au}(\mathrm{Ge})$ contacts heat treated with and without caps are similar (Fig. 5). In both cases, metallization includes AuGa phase, ternary AuGeAs phase and

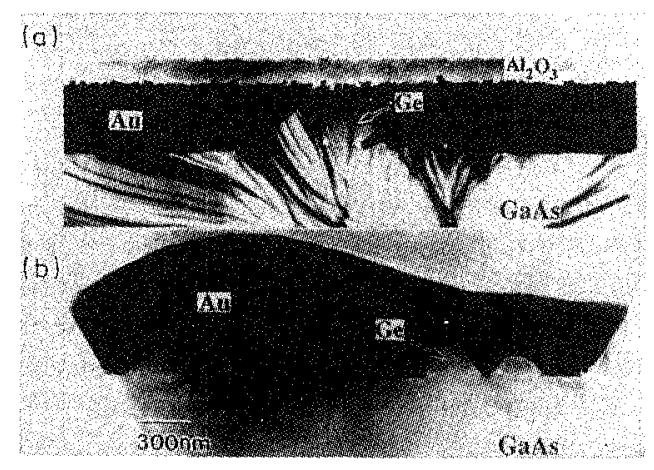

Fig. 5. TEM micrograph of $n$-GaAs/ $300 \mathrm{~nm} \mathrm{Au}(\mathrm{Ge})$ contact annealed at $420^{\circ} \mathrm{C}$ for 3 min: (a) with an $\mathrm{Al}_{2} \mathrm{O}_{3}$ cap and (b) withont a cap.

triangle-shaped Ge islands. Both contacts exhibit microscopically flat interface. The only difference is that the capped contact exhibits a smooth surface, while the uncapped is rough.

The results as a whole indicate that the use of $\mathrm{Au}$ as the main component of the metallization inevitably implies the choice of such dopants which are electrically active when placed on Ga sites. They also suggest that Au-based ohmic contacts are more controllable than commonly believed. As for contacts to $p-i, j$ e GaAs it was proved that reducing the thickness of metallization and keeping the system closed during heat treatment homogeneous $\mathrm{Au}(\mathrm{Zn})$ contacts, with limited depth of penetration can be obtained. As for $n$-type GaAs additional elements are 
needed to modify the contact reaction. A good example of improved AuGe-based metallization to $n$-type GaAs is the contact proposed by Y.-C. Shih et al. [52]. The metallization consists of $\mathrm{Ni} / \mathrm{AuGe}(27$ at.\% Ge)/Ni/Au sandwich. Of primary importance to achieve a homogeneous interface and a low contact resistance was the adequate proportion between metallization elements, as well as the sequence of deposition.

\subsubsection{Gold-free ohmic contacts}

The search for more controllable ohmic contacts pushed investigations toward gold-free metallizations. The mechanism of solid state regrowth of heavily doped or alloyed compound semiconductor layers for ohmic contact purpose has been proposed by Sands et al. [53]. The principle of the method relies on the reaction-driven decomposition of intermediate ternary phases at the contact interface. The reaction occurs well below the melting point of these interfacial phases. Metallization consists of two elements $\mathrm{M}$ and $\mathrm{N}$ deposited sequentially and chosen such that a metal $M$ reacts with a III-V compound $A B$ at low temperatures to form a ternary phase $\mathrm{M}_{x} \Lambda \mathrm{B}$ :

$$
x \mathrm{M}+\mathrm{AB} \rightarrow \mathrm{M}_{x} \mathrm{AB} .
$$

Element $N$, at higher temperatures, reacts with $M_{x} A B$ phase and forms an $M_{x} N_{y}$ compound which is sufficiently stable to dive the regrowth of $\mathrm{N}$-doped $\mathrm{AB}$ semiconductor

$$
y \mathrm{~N}+\mathrm{M}_{x} \mathrm{AB} \rightarrow \mathrm{AB}(: \mathrm{N})+\mathrm{M}_{x} \mathrm{~N}_{y}
$$

or $\mathrm{N}_{z} \mathrm{~A}_{1-z} \mathrm{~B}$ semiconductor alloy

$$
(y+z) \mathrm{N}+\mathrm{M}_{x} \mathrm{AB} \rightarrow \mathrm{N}_{z} \mathrm{~A}_{1-z} \mathrm{~B}+\mathrm{M}_{x} \mathrm{~N}_{y} .
$$

Nickel, palladium, and cobalt offer the chance to use the first step of the reaction. They were shown to react with GaAs at temperatures below $300^{\circ} \mathrm{C}$ and to form ternary compounds. Silicon, germanium and indium are possible candidates to drive the second step. Si and Ge, owing to their doping capabilities and the thermal stabilities of silicides and germanides should promote the regrowth mechanism according to the reaction (2a). Indium is known to form stable $\mathrm{In}_{x} \mathrm{Ga}_{1-x} \mathrm{As}$ compounds and should allow, at higher annealing temperatures, the regrowth mechanism according to the reaction $(2 \mathrm{~b})$. Through the judicious choice of film thicknesses and annealing temperatures both types of solid state regrowth were accomplished in practice.
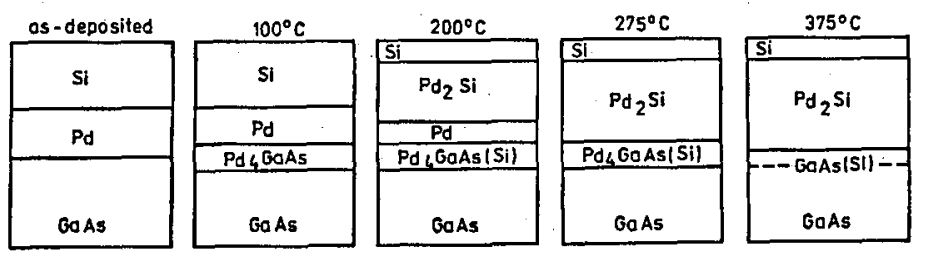

Fig. 6. Schematic cross-section of $\mathrm{GaAs} / \mathrm{Pd}(75 \mathrm{~nm}) / \mathrm{Si}(100 \mathrm{~nm})$ contact at various stages of thermal reaction $[54,55]$.

Figure 6 shows the evolution of $\mathrm{Si} / \mathrm{Pd} / \mathrm{GaAs}$ system as deduced from Rutheford backscattering (RBS), X-ray diffraction (XRD) and TEM analysis [54, 55]. 
At the early stage of reaction, at temperatures below $100^{\circ} \mathrm{C}$, an epitaxial layer of $\mathrm{Pd}_{4} \mathrm{GaAs}$ forms at the $\mathrm{Pd} / \mathrm{GaAs}$ interface. Under heat treatment at $200-275^{\circ} \mathrm{C}$ $\mathrm{Pd}_{2} \mathrm{Si}$ forms at the $\mathrm{Pd} / \mathrm{Si}$ interface and both interfaces move towards each other. Since the structures of $\mathrm{Pd}_{2} \mathrm{Si}$ and $\mathrm{Pd}_{4} \mathrm{GaAs}$ are almost identical and $\mathrm{Si}$ is known to diffuse easily through $\mathrm{Pd}_{2} \mathrm{Si}$ at low temperatures, it is believed that $\mathrm{Si}$ diffuses into $\mathrm{Pd}_{4} \mathrm{GaAs}$ as well. At $375^{\circ} \mathrm{C}$ the reaction-driven epitaxial regrowth of a thin silicon-doped GaAs layer takes place. If the initial atomic ratio of silicon to palladium is 0.65 or more, $\mathrm{Si} / \mathrm{Pd} / \mathrm{GaAs}$ contacts annealed at $375^{\circ} \mathrm{C}$ for $30 \mathrm{~min}$ are ohmic with $r_{\mathrm{c}}=(2-6) \times 10^{-6} \Omega \mathrm{cm}^{2}$ on $1 \times 10^{18} \mathrm{~cm}^{-3} n$-GaAs.

The epitaxial growth of $\mathrm{In}_{x} \mathrm{Ga}_{1-x}$ As by solid state reaction, according to formula (2b), was practically realized by Shih et al. [56]. The contact scheme, consisted of $\mathrm{Ni} / \mathrm{Ni}-\mathrm{In} / \mathrm{Ni} / \mathrm{W}$ layers deposited on (100) GaAs surface and covered by an $\mathrm{Si}_{3} \mathrm{~N}_{4}$ cap for rapid thermal annealing at $900^{\circ} \mathrm{C}$. Ohmic contact presented an interfacial microstructure with large grains of regrown $\mathrm{In}_{x} \mathrm{Ga}_{1-x} \mathrm{As}$ with $x \approx 0.3$ covering about $90 \%$ of the interface and a smooth surface.

\section{Concluding remarks}

Metal-semiconductor phenomena related to ohmic contact formation have been discussed and the mechanisms governing ohmic behavior have been analyzed. It has been shown that microstructure analysis was beneficial for the development of ohmic contact technology, and ohmic contact with low specific resistance and improved contact morphology has been achieved in recent years. However, due to the strong dependence of contact reaction on the initial state of semiconductor surface, and on the metal deposition and annealing techniques the resulting contact microstructure cannot be precisely controlled by selecting process parameters even now. In particular, for ohmic contacts fabricated in conventional vacuum systems there is, at present, little control of the surface and interface (initial surface reconstruction, residual contaminants), as well as the metallic layer growth. Without a definite breakthrough in this field no further improvements can be practically made. Also knowledge of multicomponent phase diagrams, the diffusion coefficients in multicomponent systems and the development of analytical techniques enabling to analyze the contact structure in the areas with nanometer size are needed for further progress.

So long as the advances in III-V heteroepitaxy providing the improved interface control enable band-gap engineering and new device structures, the knowledge of pretreating the surface of III-V semiconductors in order to control or at least to stabilize it during subsequent processing should open the way to interface engineering for advanced technology of ohmic contacts.

\section{References}

[1] A. Piotrowska, A. Guivarc'h, G. Pelous, Solid State Electron. 26, 179 (1983).

[2] C.J. Palmstrom, D.V. Morgan, in: Gallium Arsenide, Eds. M.J. Howes, D.V. Morgan, Wiley, Chichester 1985, p. 195.

[3] G.Y. Robinson, in: Physics and Chemistry of III-V Compound Semiconductor Interfaces, Ed. C.W. Wilmsen, Plenum Press, New York 1985, p. 73. 
[4] T. Sands, Mater. Sci. Eng. B 1, 289 (1989).

[5] A. Piotrowska, E. Kaminiska, Thin Solid Films 193/194, 511 (1990).

[6] M. Murakami, Mater. Sci. Rep. 5, 273 (1990).

[7] T.C. Shen, G.B. Gao, H. Morkoc, J. Vac. Sci. Technol. B 10, 2113 (1993).

[8]'W. Schottky, Naturwissenschaften 26, 843 (1938).

[9] W. Monch, in: Electronic Structure of Metal-Semiconductor Contacts, Ed. W. Monch, Vol. 1, Kluwer Academic Publ., Dordrecht 1990, p. 1.

[10] W.E. Spicer, in: Semiconductors and Semimetals, Eds. R.K. Willardson, A.C. Beer, E.R. Weber, Vol. 38, Academic Pris, Boston 1993, p. 449.

[11] J. Bardeen, Phys. Rev. 71, 717 (1947).

[12] R.Z. Bachrach, R.S. Bauer, J. Vac. Sci. Technol. 16, 1149 (1979).

[13] R.Z. Bachrach, R.S. Bauer, P. Chiaradia, G.V. Hansson, J. Vac. Sci. Technol. 19, 335 (1981).

[14] J.R. Waldrop, J. Vac. Sci. Technol. B 2, 445 (1984).

[15] J.R. Waldrop, J. Vac. Sci. Technol. B 3, 1197 (1985).

[16] J.R. Waldrop, Appl. Phys. Lett. 47, 1301 (1985).

[17] J.R. Waldrop, R.W. Grant, Appl. Phys. Lett. 50, 250 (1987).

[18] J.R. Waldrop, R.W. Grant, J. Vac. Sci. Technol. B 6, 1432 (1988).

[19] T. Yokatsuka, T. Narusawa, Y. Uchida, H. Nakashima, Appl. Phys. Lett. 50, 591 (1987).

[20] Y. Uchida, T. Yokotsuka, H. Nakashima, S. Takatani, Appl. Phys. Lett. 50, 670 (1987).

[21] C. Laubschat, M. Prietsch, M. Domke, E. Weschke, G. Remmers, T. Mandel, J.E. Ortega, G. Kaindl, Phys. Rev. Lett. 62, 1306 (1989).

[22] J.M. Woodall, J.L. Freeouf, G.D. Pettit, T. Jackson, P. Kirchner, J. Vac. Sci. Technol. 19, 626 (1981).

[23] Y. Shiraishi, T. Yoshida, N. Furuhata, A. Okamoto, in: Gallium Arsenide and Related Compounds, Inst. Phys. Conf. Ser., Vol. 129, Eds. T. Ikegami, F. Hasegawa, Y. Takeda, Inst. of Physics Publ., Bristol 1993, p. 639.

[24] R. Beyers, K.B. Kim, R. Sinclair, J. Appl. Phys. 61, 2195 (1987).

[25] A. Lakhani, J. Appl. Phys. 56, 1888 (1984).

[26] A. Lahav, M. Eizenberg, Y. Komen, J. Appl. Phys. 60, 991 (1986).

[27] D.E. Savage, M.G. Lagally, J. Vac. Sci. Technol. B 4, 943 (1986).

[28] J. Ding, J. Washburn, T. Sands, V.G. Keramidas, Appl. Phys. Lett. 49, 818 (1986).

[29] H.J. Kim, M. Murakami, W.H. Price, M. Norcott, J. Appl. Phys. 67, 4183 (1990).

[30] M. Murakami, Y.C. Shih, W.H. Price, E.L. Wilkie, A.C. Callegari, J. Appl. Phys. 64, 1974 (1988).

[31] J.F. McGilp, J. Mater. Res. 2, 516 (1987).

[32] A. Hiraki, K. Shuto, S. Kim, W. Kammura, M. Iwami, Appl. Phys. Lett. 31, 611 (1971).

[33] R.S. Williams, J.R. Lince, T.C. Tsai, J.H. Pugh, in: Thin Films - Interfaces and Phenomena, Mater. Res. Symp. Symposia Proc., Vol. 54, Eds. R.J. Nemanich, P.S. Ho, S.S. Lau, MRS, Pittsburgh 1986, p. 335. 
[34] J.H. Pugh, R.S. Williams, J. Mater. Res. 1, 343 (1986).

[35] C.J. Cooke, W. Hume-Rothery, J. Less-Common Met. 10, 42 (1966).

[36] T. Yoshii, C.L. Bauer, A.G. Milnes, Thin Solid Films 111, 149 (1984).

[37] T. Sands, C.C. Chang, A.S. Kaplan, V.G. Keramidas, K.M. Krishnan, J. Washburn, J. Appl. Phys. 50, 1346 (1987).

[38] J.-C. Lin, K.J. Schulz, K.-C. Isieh, Y.A. Chang, J. Electrochem. Soc. 136, 3006 (1989).

[39] A. Lahav, M. Eizenberg, Y. Komen, J. Appl. Phys. 60, 991 (1986).

[40] T. Sands, V.G. Keramidas, A.J. Yu, K.-M. You, R. Gronsky, J. Washburn, J. Maler. Res. 2, 262 (1987).

[41] A. Piotrowska, E. Kamińska, A. Barcz, J. Adamczewska, A. Turos, Thin Solid Films 130, 231 (1985).

[42] E. Kamińska, A. Piotrowska, A. Barcz, J. Adamczewska, A. Turos, Solid State Electron. 29, 279 (1986).

[43] A. Barcz, E. Kamińska, A. Piotrowska, Thin Solid Films 149, 251 (1987).

[44] A. Piotrowska, E. Kaminiska, M. Guziewicz, R. Veresegyhasy, I. Mojzes, B. Pecz, Acta Phys. Pol. A 80, 457 (1991).

[45] X.W. Lin, Z. Liliental-Weber, J. Washburn, A. Piotrowska, E. Kamińska, in: $A d-$ vanced Metallization and Processing for Semiconductor Devices and Circuits II, Mater. Res. Soc. Symp. Proc., Vol. 260, Eds. A. Katz, Y.I. Nissim, S.P. Murarka, J.M.E. Harper, MRS, Pittsburg 1992, p. 469.

[46] E. Kamińska, A. Piotrowska, R. Żarecka, A. Barcz, E. Mizera, S. Kwiatkowski, Acta Phys. Pol. A 82, 853 (1992).

[47] A. Piotrowska, E. Kaminiska, S. Kwiatkowski, A. Turos, J. Appl. Phys. 73, 4404 (1993).

[48] X.W. Lin, Z. Liliental-Weber, J. Washburn, A. Piotrowska, E. Kamińska, J. Vac. Sci. Technol. B 11, 44 (1993).

[49] A. Piotrowska, E. Kamińska, X.W. Lin, Z. Liliental-Weber, J. Washburn, E. Weber, S. Gierlotka, J. Adamczewska, S. Kwiatkowski, A. Turos, J. Vac. Sci. Technol. B 11, (1993).

[50] X.W. Lin, A. Piotrowska, E. Kaminiska, Z. Liliental-Weber, J. Washburn, in: III-IV Electronic and Photonic Device Fabrication and Performance, Mater. Res. Soc. Symp. Proc., Vol. 300, Eds. K.S. Jones, S.J. Pearton, H. Kanber, MRS, 1993, in press.

[51] E. Kamińska, A. Piotrowska, J. Adamczewska, R. Żarecka, E. Mizera, in Ref. [50], in press.

[52] Y.-C.Shih, M. Murakami, E.L. Wilkie, A.C. Callegari, J. Appl. Phys. 62, 582 (1987).

[53] T. Sands, E.D. Marshall, L.C. Wang, J. Mater. Res. 3, 914 (1988).

[54] L.S. Yu, L.C. Wang, E.D. Marshall, S.S. Lau, T.F. Kuech, J. Appl. Phys. 65, 1621 (1989):

[55] L.C. Wang, B. Zhang, F. Fang, E.D. Marshall, S.S. Lau, T. Sands, T.F. Kuech, J. Mater. Res. 3, 922 (1988).

[56] Y.-C. Shih, M. Murakami, W.H. Price, J. Appl. Phys. 65, 3539 (1989). 